\title{
Hydroconversion of Residual Fatty Acids on a Molybdenum-Copper Catalyst
}

\author{
DAN ION ${ }^{1}$, MIHAELA BOMBOȘ ${ }^{2 *}$, GABRIEL VASILIEVICI ${ }^{2}$, ADRIAN RADU ${ }^{2}$, PAUL ROȘCA ${ }^{1 *}$ \\ ${ }^{1}$ Petroleum-GasUniversity of Ploieşti, 39 Bucuresti Blvd., 100680, Ploiesti, Romania \\ ${ }^{2}$ National Institute for Research Development for Chemistry and Petrochemistry- ICECHIM-Bucuresti, 202 Splaiul \\ Independetei, 060021, Bucharest, Romania
}

The molybdenum-copper catalyst was prepared by impregnating with an aqueous precursors solution by the pore filling method. The catalyst was characterized by determining the acid strength and textural characteristics. The catalyst contains predominantly weak acidic centers and the average pore diameter is $4.3 \mathrm{~nm}$. Conversion of residual fatty acids into deoxygenated liquid were carried out on a laboratory equipment in continuous system using a fixed bed catalytic reactor. The reaction products where mainly linear hydrocarbons C15, C16, C17 and C18 and shorter chain hydrocarbons <C15 and no oxygenated products, alkene or iso-alkane were identified. The yield in hydrocarbons obtained by decarboxylation I decarbonylation and by hydrocraking are lower than the yield in hydrocarbons obtained by hydrodeoxygenation.

Keywords: residual fatty acids, biofuel, hydroconversion, catalyst acidity, $\mathrm{Co}, \mathrm{Mo}, \gamma-\mathrm{Al}_{2} \mathrm{O}_{3}$

Triglycerides can be used directly in diesel engines, but direct combustion can cause many engine problems, due to the high viscosity and low volatility of triglycerides, such as: carbon deposits and injector coking [1]. Direct hydroconversion of triglycerides into hydrocarbons is a variant viable to eliminate these drawbacks [2-4].

Obtaining green fuel by hydroconversion represents a solution to solve the global problem of clean energy [5-7]. The application of catalytic technology for the transformation of oils into green diesel has great potential for industrial application. The main problem for developing green diesel technologies is the limited number of non-food triglyceride sources of fatty acids [8].

Hydrotreatment reactions are extremely exothermic, their control being extremely important. These reactions have been usually applied to remove heteroatoms such as sulfur, oxygen and nitrogen from various oil fractions and occur in the presence of metal and acid catalytic centers [9-12]. Impurities from animal oils or fats, high reaction temperature, insufficient control of the reaction temperature or too little hydrogen in the reactor can lead to unwanted side reactions, such as cracking, polymerization, ketonization, cyclization and aromatization and deposition of coke on the catalyst.

Hydroconversion results from several competing reactions, such as decarboxylation [13], decarbonylation [14-16] and hydrodeoxygenation [17].Snare et al. [18] used oleic acid, linoleic acid and methyl oleate as model compounds in vegetable oil, for hydroconversion on a semi-continuous reactor, using a 5\% Pd / C catalyst, resulting in high selectivity and high yields in hydrocarbons. They observed that the hydroprocessing of unsaturated acids takes place through the initial hydrogenation of the double bonds, followed by deoxygenation of the saturated acid. Also, prior to hydrogenation, intermediate isomerization reactions occur, e.g. isomerization of oleic acid to elaidic acid. Mostly n-heptadecane was identified, as well as small amounts of position isomers of the respective olefin (1-, 3-, and 8-heptadecene) and C17 aromatic compounds.

The hydrodeoxygenation of stearic acid on commercial Pd catalysts deposited on coal, (Pd / C (1\% and 5\% Pd), was studied by Stepacheva and his team [19], for 280 minutes at 528K and $0.6 \mathrm{MPa}$, obtaining mostly n-heptadecane, with a selectivity of $97 \%$ (1\% Pd / C) and $88 \%$ (5\% Pd / C), indicating that on Pd catalysts, the hydroconversion process of saturated fatty acids it proceeds by the decarbonylation mechanism, and that of the unsaturated fatty acids occurs in two stages (i) hydrogenation of the double bond; (ii) decarbonylation of the saturated acids with the formation of hydrocarbons. cracking - The kinetic model developed by Arora et al. [20], regarding the hydrodeoxygenation of stearic acid on NiMo catalyst, takes into account a simplified scheme of hydroconversion reactions containing all three hydroconversion pathways: decarboxylation, decarbonylation and hydrodeoxygenation: In the temperature range 548-598K and at pressures of 40-70 bar, C17 and C18 alkane isomers are mainly present. At all temperatures tested the rate of formation of the decarbonate products was higher than that of the directly hydrogenated oxygen products.

*email: bombos.mm@gmail.com; prosca@upg-ploiesti.ro 
The possible reaction pathways for triolein hydroconversion on $\mathrm{Ni}$, Co and Mo catalysts on alumina support have been studied by Horacek et al. They observed that triolein was initially hydrogenated and then completely transformed into singlechain products in the form of di- and monoglycerides with small amounts of stearic acid, as an intermediate product. The stearic acid was converted into $\mathrm{C} 17$ and $\mathrm{C} 18$ hydrocarbons by two hydrodeoxygenation and decarboxylation / decarbonylation reaction pathways. By hydrodeoxygenation, octadecane $(\mathrm{C} 18)$ and propane were formed, and by decarboxylation / decarbonylation, the carboxyl groups were removed as $\mathrm{CO}_{2}$ and $\mathrm{CO}$. The difference in the distribution of products of different model compounds indicates that the catalytic activity depends on the degree of unsaturation of the raw material. The authors found the NiMo catalyst to be the most active catalyst in the temperature range of $250{ }^{\circ} \mathrm{C}$ and $270^{\circ} \mathrm{C}$. At the same temperature range, on the $\mathrm{CoMo} / \mathrm{Al} 2 \mathrm{O} 3$ catalyst, the hydrodeoxygenation reaction is half selective [21].

The activity of hydrodeoxygenation catalysts, selectivity to hydrocarbons and the mechanism of deoxygenation are mainly influenced by the presence of acid catalytic centers. As in the case of hydrodesulfurization and of other hydrogenation reactions, the presence of acid catalytic centers, with a certain distribution of their strength, is essential in the development of the respective processes [22, 23].

The increase in the production of refined vegetable oils has led to an equivalent increase in the quantity of by-products resulting in the refining of these fats. Capitalizing on them by introducing them into the circular economy is a priority for the next period. In this paper we studied the hydroconversion process of the residual fraction of fatty acids, resulting in the refining of sunflower vegetable oil, on a Co-Mo catalyst deposited on $\gamma-\mathrm{Al}_{2} \mathrm{O}_{3}$.

\section{Experimental part}

\section{Catalyst preparation and characterization}

The catalyst support is $\gamma-\mathrm{Al}_{2} \mathrm{O}_{3}$ in extruded form, from Alfa Aesar. The catalysts were prepared by successive impregnation with pore filling method. The catalytic precursors were aquous solution of ammonium molybdate heptahydrate (99.98\% Sigma Aldrich), and copper nitrate (purum p.a. Sigma-Aldrich). After every impregnation at room temperature, the catalytic precursor was dried at ambient temperature for $6 \mathrm{~h}$ and calcinated at $500^{\circ} \mathrm{C}$ for $6 \mathrm{~h}$.

Catalyst characterization was performed by determining the acid strength and textural characteristics. The acid strength distribution of the active center has been determined by the method of thermal desorption of diethyl-amine on a DuPont Instruments Thermal Analyst 2000/2100 coupled with a module 951 Thermogravimetric Analizer. Textural characteristics of the catalyst (surface area, pore volume, average pore diameter, pore-size-distribution) were determined on a Autosorb 1 Quantacrome.

Hydroconversion of the residual fraction of fatty acids from sunflower oil, was carried out on a continuous reactor, with a fixed catalyst layer, in which the reactants are introduced into the reactor through the upper part of the reactor.

The raw material used to study the hydroconversion process was an oil by-product resulting from the splitting of the soap-stock in refining sunflower oil - the residual fraction of sunflower fatty acids, with the characteristics mentioned in Table 1. The main components are fatty acids and glycerides derived from sunflower oil.

Table 1

CHARACTERISTICS OF THE RESIDUAL FRACTION OF SUNFLOWER FATTY ACIDS

\begin{tabular}{|c|c|}
\hline $\begin{array}{c}\text { Properties of the residual fraction of fatty acids from } \\
\text { sunflower }\end{array}$ & Value \\
\hline Density, $15^{\circ} \mathrm{C}, \mathrm{g} / \mathrm{cm}^{3}$ & 0.9 \\
\hline Acidity value, $\mathrm{mgKOH} / \mathrm{g}$ & 90 \\
\hline Fats, $\%$ & 95 \\
\hline Saponification index, $\mathrm{mgKOH} / \mathrm{g}$ & 186.4 \\
\hline Apparent average molecular mass, $\mathrm{kg} / \mathrm{kmol}$ & 290 \\
\hline
\end{tabular}

The experiments were carried out in the following experimental conditions: temperature (T): ranging from $300^{\circ} \mathrm{C}$ to $340^{\circ} \mathrm{C}$, pressure (p) from 50 bar to 70 bar and the liquid hourly space velocity (LHSV) from $0.2 \mathrm{~h}^{-1}$ to $0.4 \mathrm{~h}^{-1}$. The feedstock consisted of residual fraction of fatty acids and hexane as a solvent, with residual fraction of fatty acids concentration of 5 wt $\%$, was introduced by a metering pump.

The composition of the reaction mixture was performed by gas chromatography (Varian 3800) coupled with mass spectrometry (Varian 4000), equipped with Agilent VF-5ms capillary column. The carrier gas was He.

The conversion of the residual fraction of fatty acids from sunflower $\left(\mathrm{C}_{\mathrm{x}}\right)$ was determined on the basis of the saponification index of the raw material and the reaction products: 


$$
C_{x}(\%)=\left[\left(C_{\text {Sap.mp }}-C_{\text {Sap. } i}\right) / C_{\text {Sap.mp }}\right] x 100,
$$

- $\mathrm{C}_{\text {Sap.mp }}$, represents the saponification value of the raw material, in $\mathrm{mg} \mathrm{KOH} \mathrm{/} \mathrm{g} \mathrm{raw} \mathrm{material;}$

- $\mathrm{C}_{\text {Sap.i }}$, represents the saponification value of the reaction product, in $\mathrm{mg} \mathrm{KOH} / \mathrm{g}$ sample;

Yield of linear hydrocarbons obtained by cracking $(<\mathrm{n}-\mathrm{C} 15)$ :

$$
\eta C_{<15}, \%=\left(\text { sum of moles linear hydrocarbons } C_{\leq 15} \text { : sum of moles components) } x 100\right. \text {; }
$$

Yield in hydrocarbons obtained by decarboxylation / decarbonylation (pentadecane and heptadecane):

$$
\eta C_{15+17} \%=\text { (sum of moles } n-C_{15+17} / \text { sum of moles components) } x 100 \text {; }
$$

Yield in hydrocarbons obtained by hydrodeoxygenation (hexadecane and octadecane):

$$
\eta C_{16+18}, \%=\left(\text { sum of moles } n-C_{16+18} / \text { sum of moles components) } x 100\right. \text {; }
$$

Yield in other products (hydrocarbons $\mathrm{C}_{>18}$, oxygenated compounds):

$\eta$ other products, $\%=[$ sum of moles (hydrocarbons $C>18$, oxygenated compounds) $/$

/sum of moles components] $x 100$;

\section{Results and discussions}

Diethylamine thermodesorption curves of the catalyst, from 20 to $600^{\circ} \mathrm{C}$, are shown in Figure 1 . The three zones are assigned to weak, medium, and strong acidities. The weak acidic centers are obtained in the first region which ranges from $160^{\circ} \mathrm{C}$ to $300^{\circ} \mathrm{C}$, the medium acidic centers are in the second region from $300^{\circ} \mathrm{C}$ to $450^{\circ} \mathrm{C}$ and the strong acidic centers are in the last region from $450^{\circ} \mathrm{C}$ to $600^{\circ} \mathrm{C}$.

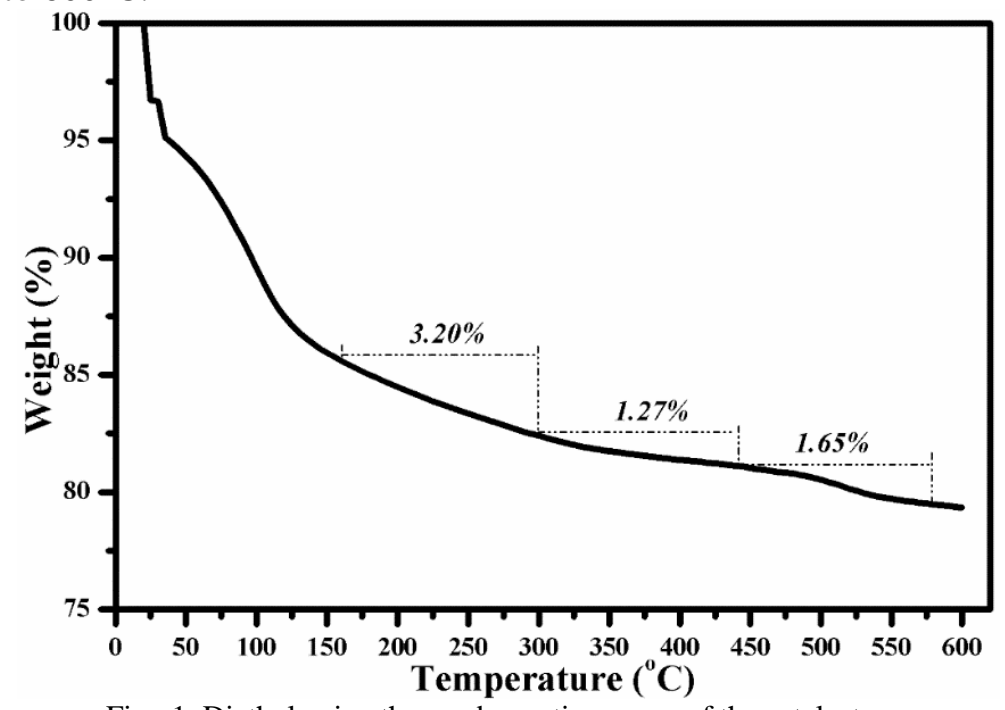

Fig. 1. Diethylamine thermodesorption curve of the catalyst

The concentration of strongly acidic centers is $0.226 \mathrm{meq} / \mathrm{g}$, the concentration of the medium strength centers is 0.174 meq / $\mathrm{g}$ and that of the weak acid centers is $0.438 \mathrm{meq} / \mathrm{g}$ (Table 2).

Table 2

PORES ACID STRENGTH DISTRIBUTION OF THE CATALYST
\begin{tabular}{|c|c|}
\hline Acidic centers & $\begin{array}{c}\text { Concentration } \\
(\mathbf{m e q} / \mathbf{g})\end{array}$ \\
\hline Weak acidic centers & 0.438 \\
\hline Medium-strength acid centers & 0.174 \\
\hline Strong acidic centers & 0.226 \\
\hline Total acidity & $\mathbf{0 . 8 3 8}$ \\
\hline
\end{tabular}

The pore distribution and the pore volume according to the radius were calculated according to the volume adsorbed at the relative pressure of 0.99 , using the desorption branch of the isotherms, using the Barrett Joyner-Halenda (BJH) method.The adsorption / desorption isotherm and pore size distribution of the $10 \% \mathrm{Mo} \% \mathrm{Cu} / \gamma-\mathrm{Al}_{2} \mathrm{O}_{3}$ catalyst are shown in Figures 2-3. 


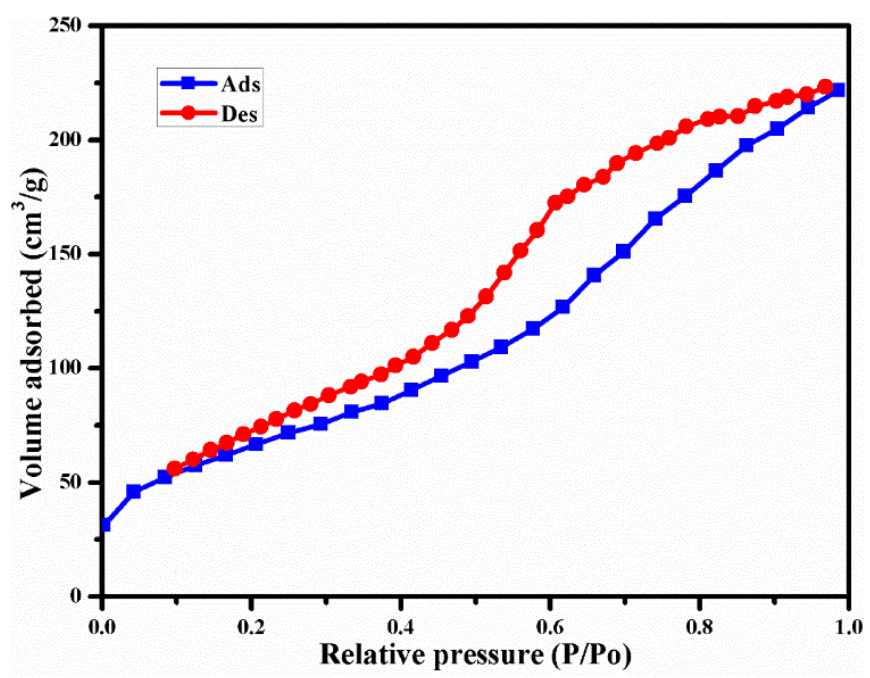

Fig. 2. The isotherm of nitrogen adsorption / desorbtion

The adsorption isotherm is of type IV and has a hysteresis loop of type E. The volume of adsorbed nitrogen is reduced to relative pressures $(\mathrm{w} / \mathrm{w})$ of 0.1 , due to its monolayer adsorption on the surface of the catalyst.

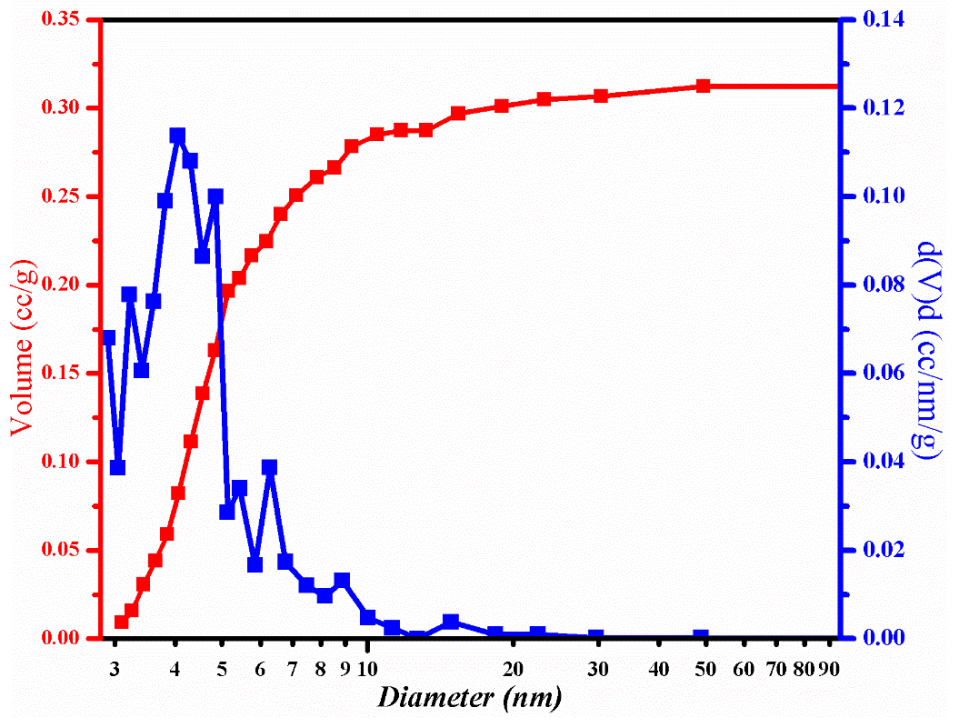

Fig. 2. Pore size distributions of the catalyst

The mesopore size distribution of the catalyst is between 2 and $11 \mathrm{~nm}$ (Figure 3). Total pore volume, determined by the $\mathrm{BJH}$ method is $0.312 \mathrm{~cm} 3 / \mathrm{g}$ and the average pore diameter is $4.314 \mathrm{~nm}$ (Table 3).

Table 3

TEXTURAL PROPERTIES OF THE CATALYST

\begin{tabular}{|c|c|c|}
\hline $\begin{array}{c}\text { Specific surface BET, } \\
\left(\mathbf{m}^{\mathbf{2}} / \mathbf{g}\right)\end{array}$ & Pore volume, $\left(\mathbf{c m}^{\mathbf{3}} \mathbf{/ g}\right)$ & $\begin{array}{c}\text { Average pore diameter, } \\
(\mathbf{n m})\end{array}$ \\
\hline 124.11 & 0.312 & 4.314 \\
\hline
\end{tabular}

From the analysis of the reaction products, mainly linear hydrocarbons $\mathrm{C} 15, \mathrm{C} 16, \mathrm{C} 17$ and $\mathrm{C} 18$ and shorter chain hydrocarbons < 15 were identified. No oxygenated products (alcohols or esters), alkenes or iso-alkanes have been identified. In the other products category were considered hydrocarbons with $\mathrm{C}>18$ atoms, which were identified with small percentages. Figure 4 shows an example of a chromatogram obtained by GC-MS analysis of the reaction products obtained by hydrotreating the residual fraction of sunflower fatty acids, on the catalyst $10 \% \mathrm{Mo} \% \mathrm{Cu} / \gamma-\mathrm{Al}_{2} \mathrm{O}_{3}$ to $300^{\circ} \mathrm{C}$, pressure of 50 bar and LHSV of $0.2 \mathrm{~h}^{-1}$. 


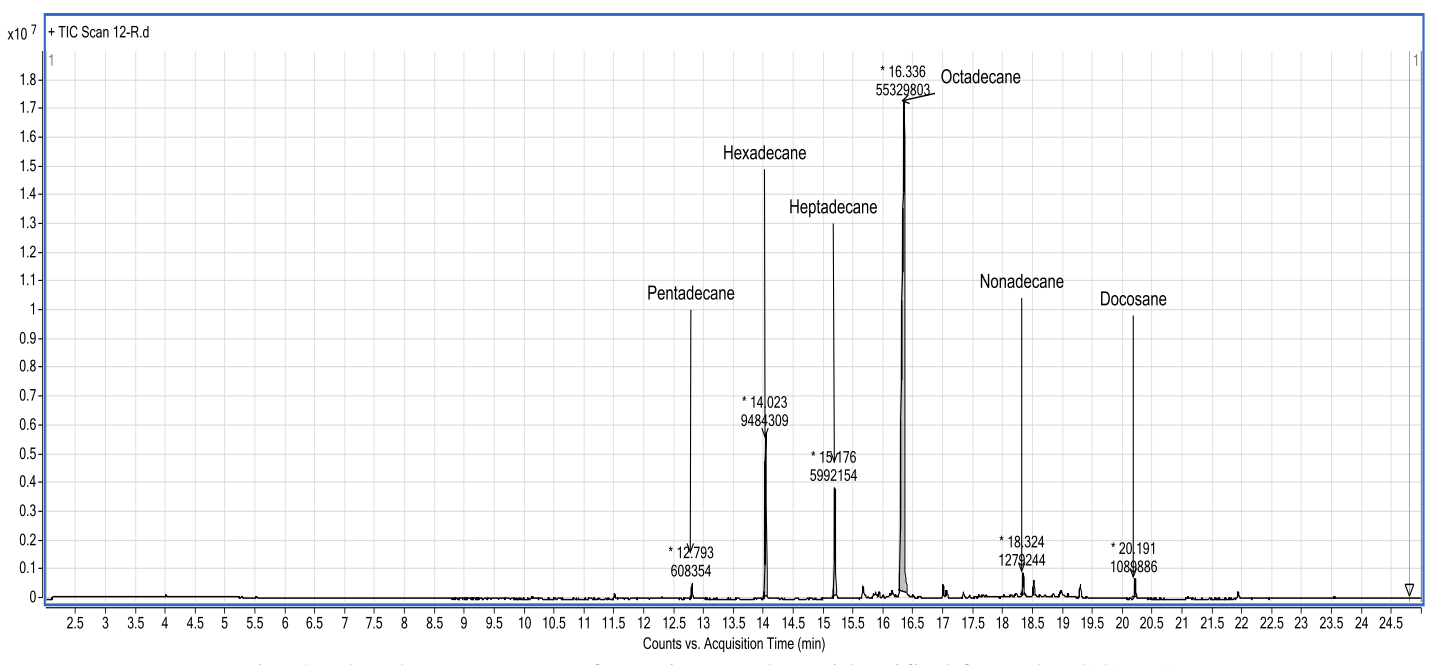

Fig. 4. The chromatogram of reaction products identified from the GC-MS

Figure 47 shows the variation of the conversion of the raw material, with temperature, in the range $300^{\circ} \mathrm{C}-340^{\circ} \mathrm{C}$. It is observed that, during this interval, the conversion of the raw material is $>90 \%$ and increases with the increase of temperature, up to $95.6 \%$ at $340^{\circ} \mathrm{C}$, pressure of 50 bar and LHSV of $0.2 \mathrm{~h}^{-1}$.

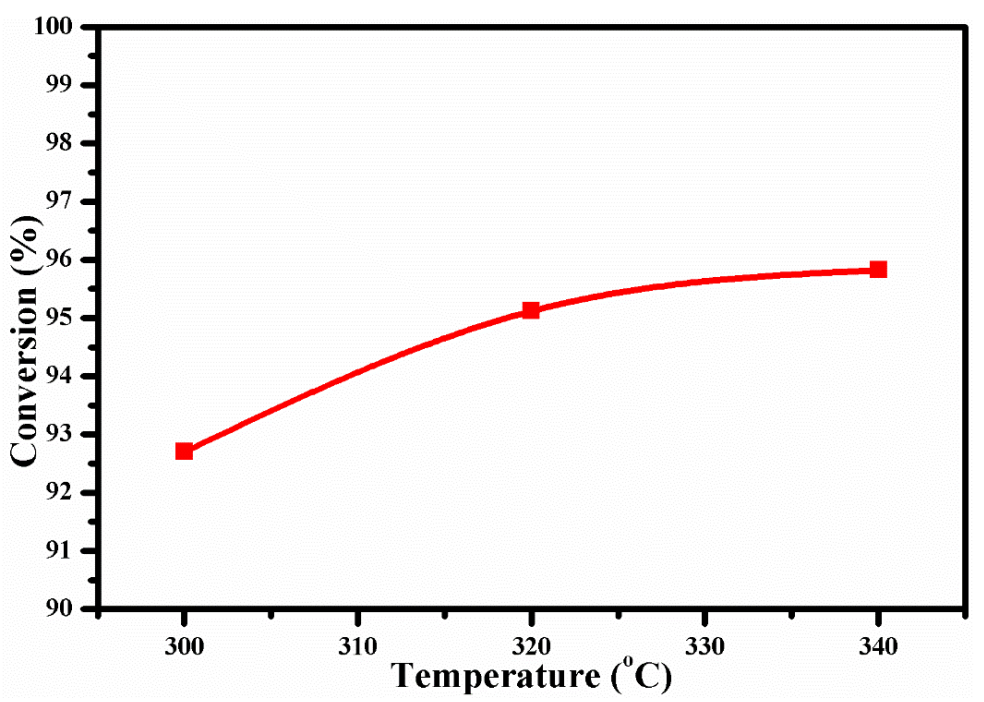

Fig. 5. Influence of reaction temperature onthe conversion at 50 bar and LHSV $0.2 \mathrm{~h}^{-1}$

The yields in the reaction products, for the catalyst $10 \% \mathrm{Mo5} \% \mathrm{Cu} / \gamma-\mathrm{Al}_{2} \mathrm{O}_{3}$, at temperatures between $300{ }^{\circ} \mathrm{C}-340$ ${ }^{\circ} \mathrm{C}$ and pressure and LHSV of 50 bar respectively, $0.2 \mathrm{~h}-1$, is shown in Figure 6 . The yield in the linear hydrocarbons $\mathrm{n}-\mathrm{C} 18$ $+\mathrm{n}-\mathrm{C} 16$, formed on the hydrodeoxygenation reaction mechanism, is $74.14 \%$ at $300{ }^{\circ} \mathrm{C}$ and decreases with increasing temperature, reaching $73.94 \%$, at a temperature of $340{ }^{\circ} \mathrm{C}$. The yield in $\mathrm{n}-\mathrm{C} 17+\mathrm{n}-\mathrm{C} 15$ hydrocarbons, formed by decarboxylation/ decarbonylation, decreases with increasing temperature, from $19.11 \%$ to $12.45 \%$, with the increase in yield in linear hydrocarbons with carbon number $<15(<\mathrm{n}-\mathrm{C} 15)$. The increase of the yield in hydrocarbons $<\mathrm{C} 15$, at temperatures higher than $320{ }^{\circ} \mathrm{C}$, indicates that at the pressure of 50 bar and LHSV of $0.2 \mathrm{~h}^{-1}$, occur the reactions of hydrocracking of fatty acids, with fragmentation of their chains. This can be demonstrated by following the decrease of the yield in longchain linear hydrocarbons (C15-C18). 


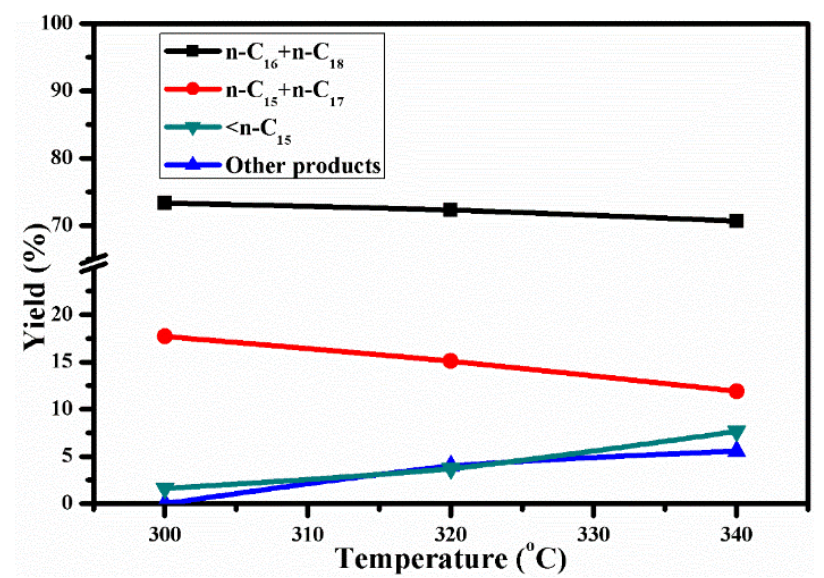

Fig. 6. The influence of temperature on the yield in reaction products at 50 bar and LHSV $0.2 \mathrm{~h}^{-1}$

To evaluate the predominant reaction mechanism for the hydroconversion of the residual fraction of sunflower fatty acids on the $10 \% \mathrm{Mo} 5 \% \mathrm{Cu} / \gamma$-Al2O3 catalyst, the influence of the reaction temperature on the molar ratios between the linear hydrocarbons n-C18 / n-C17 and the linear hydrocarbons n-C16 / n-C15 was studied. The results are shown in Figure 7. From the obtained results it can be seen that the ratio $\mathrm{n}-\mathrm{C} 18$ / n-C17, is higher than the unit, over the whole temperature range studied, thus indicating that for carboxylic acids C18, hydrodeoxygenation is more likely than decarboxylation / decarbonylation.

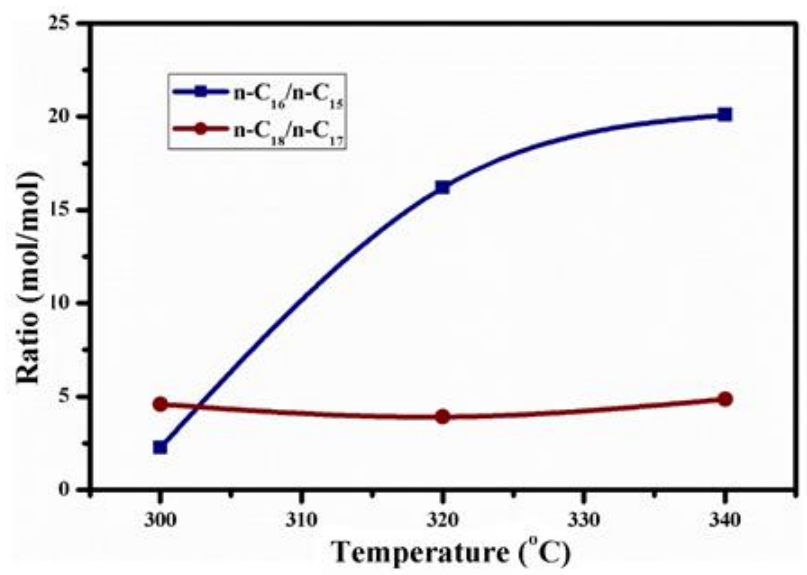

Fig.7. The influence of temperature on molar ratios $\mathrm{nC}_{18} / \mathrm{nC}_{17}$ and $\mathrm{nC}_{16} / \mathrm{nC}_{15}$ at 50 barr and LHSV $0.2 \mathrm{~h}^{-1}$

Increasing the pressure from 50 bar to $70 \mathrm{bar}$, with the constant maintenance of the other parameters $\left(340{ }^{\circ} \mathrm{C}\right.$ and $\left.0.2 \mathrm{~h}^{-1}\right)$, insignificant influences the conversion of the raw material. We can see from Figure 8 , an insignificant increase of the conversion from $95.6 \%$ at 50 bar, to only $95.8 \%$ at 70 bar.

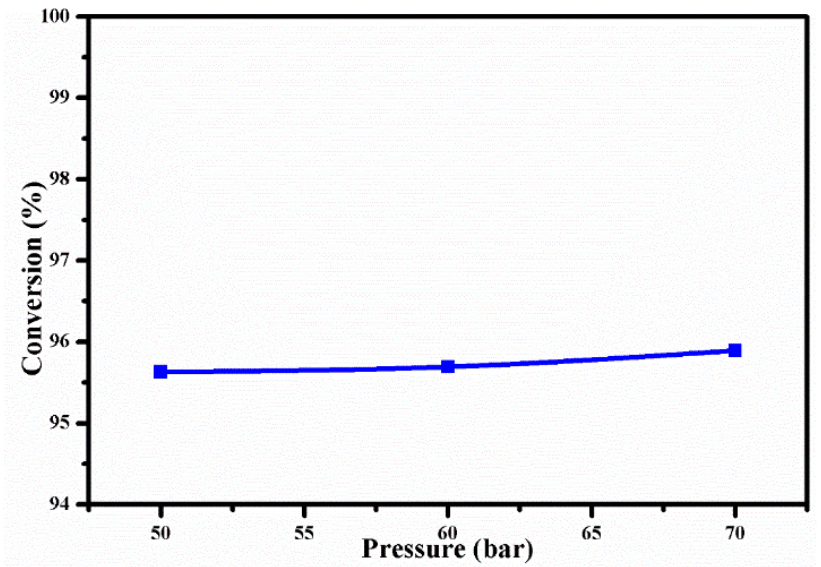

Fig.8. Variation of the conversion of the raw material with the pressure at $340^{\circ} \mathrm{C}$ and LHSVof $0.2 \mathrm{~h}^{-1}$ 
In figure 9, the influence of the pressure on the yield in reaction products at $340{ }^{\circ} \mathrm{C}$ and a volume speed of $0.2 \mathrm{~h}^{-1}$ is shown. The yield in n-C18 + n-C16 linear hydrocarbons decreases from $73.94 \%$ at 50 bar, to $65.2 \%$ at 70 bar. In contrast, the yield in linear hydrocarbons $\mathrm{n}-\mathrm{C} 18+\mathrm{n}-\mathrm{C} 16$ increased from $12.45 \%$ to $18.4 \%$. Higher pressure favors cracking reactions, yields in linear hydrocarbons with shorter chains of $15 \mathrm{C}$ atoms, decreased from $8 \%$, to $3 \%$ with increasing pressure from 50 bar to 70 bar. The increase in yield in other products $(C>18)$ indicates that oligomerization reactions at pressure greater than 50 bar are favored, probably due to the improved access to the strong acid centers of catalyst.

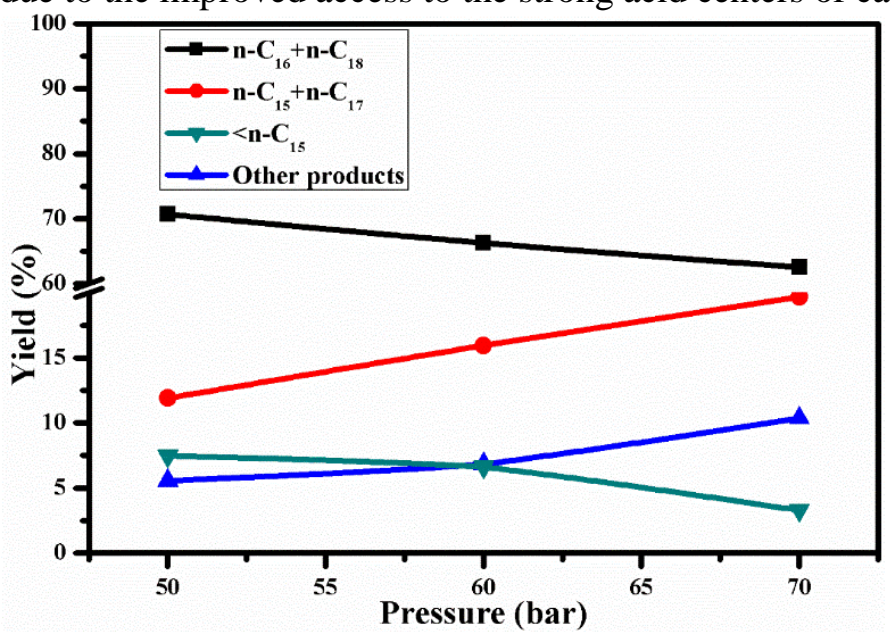

Fig.9. The influence of the pressure on the yield in reaction products, at $340^{\circ} \mathrm{C}$ and LHSV of $0.2 \mathrm{~h}^{-1}$

The molar ratio of n-C16 / n-C15 hydrocarbons increased with increasing pressure from 50 bar to 60 bar, after which it started to decrease, which shows that at pressures above 60 bar, decarboxylation / decarbonylation reactions, are beginning to intensify. For $\mathrm{C} 18$ carboxylic acids, the n-C18 / n-C17 ratio decreases almost linearly throughout the pressure range (Figure 10).

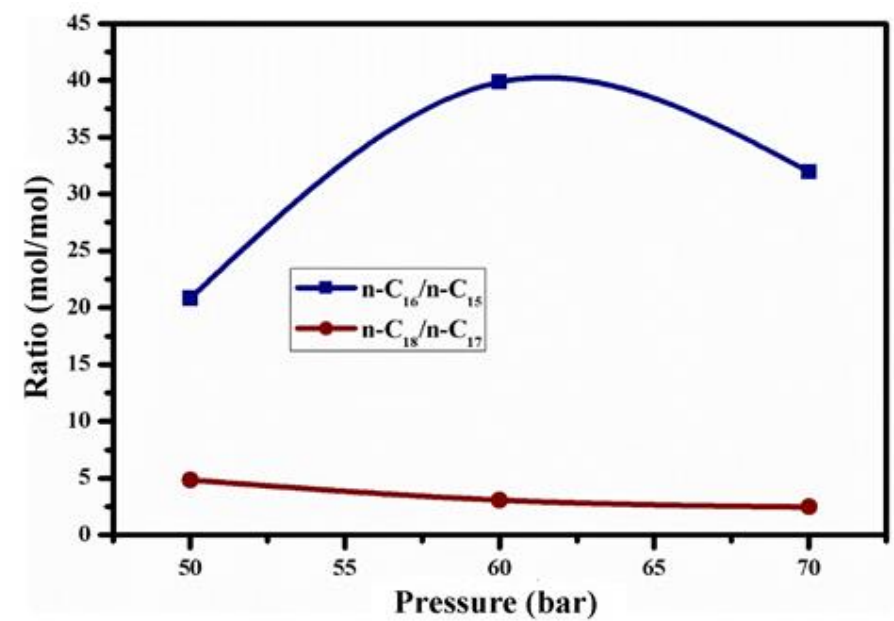

Fig.10. The influence of pressure on molar ratios $\mathrm{nC}_{18} / \mathrm{nC}_{17}$ şi $\mathrm{nC}_{16} / \mathrm{nC}_{15}$ at $340^{\circ} \mathrm{C}$ and LHSV of $0.2 \mathrm{~h}^{-1}$

In Figure 11 it is observed that the transformation of the residual fraction of fatty acids from the sunflower decreases with the increase of the LHSV. At LHSV values of $0.2 \mathrm{~h}^{-1}$ the conversion of the fatty acid residual fraction is $95.9 \%$ and at LHSV of $0.4 \mathrm{~h}^{-1}$ decreases to $93.2 \%$. The decrease of the conversion with the increase of LHSV occurs because the contact time between the catalyst and the raw material is smaller. 


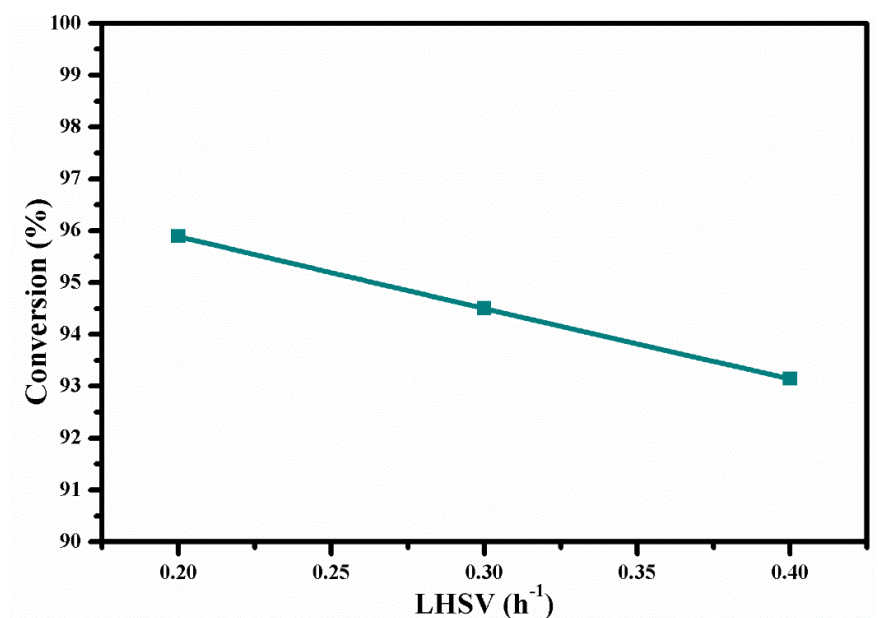

Fig. 11. Variation of the conversion of the raw material with LHSV, at $340^{\circ} \mathrm{C}$ and 70 bar

The yield in the linear hydrocarbons of interest, $\mathrm{n}-\mathrm{C} 16+\mathrm{n}-\mathrm{C} 18$ increases almost linearly, from $65.2 \%$ to $74.49 \%$ with the increase in LHSV from 0.2 to $0.4 \mathrm{~h}^{-1}$, under constant conditions. temperature $\left(340{ }^{\circ} \mathrm{C}\right)$ and pressure $(70$ bar), while the yield in $\mathrm{n}-\mathrm{C} 17+\mathrm{n}-\mathrm{C} 15$ hydrocarbons, decreases from $18.4 \%$ to $10.69 \%$ (Figure 12). Yields in <n-C15 hydrocarbons and other products ( $\mathrm{n}>\mathrm{C} 18$ ), slightly decrease with increasing of LHSV, thus a shorter contact time of the reactants on the $10 \% \mathrm{Mo} 5 \% \mathrm{Cu} / \gamma$-Al2O3 catalyst favors hydrodeoxygenation reactions over decarboxylation / decarbonylation and hydrocracking. This is also confirmed by the molar ratios n-C16 / n-C15 and n-C18 / n-C17, which at a LHSV of $0.4 \mathrm{~h}^{-1}$, are higher than at the LHSV of $0.2 \mathrm{~h}^{-1}$, as can be seen in Figure 13.

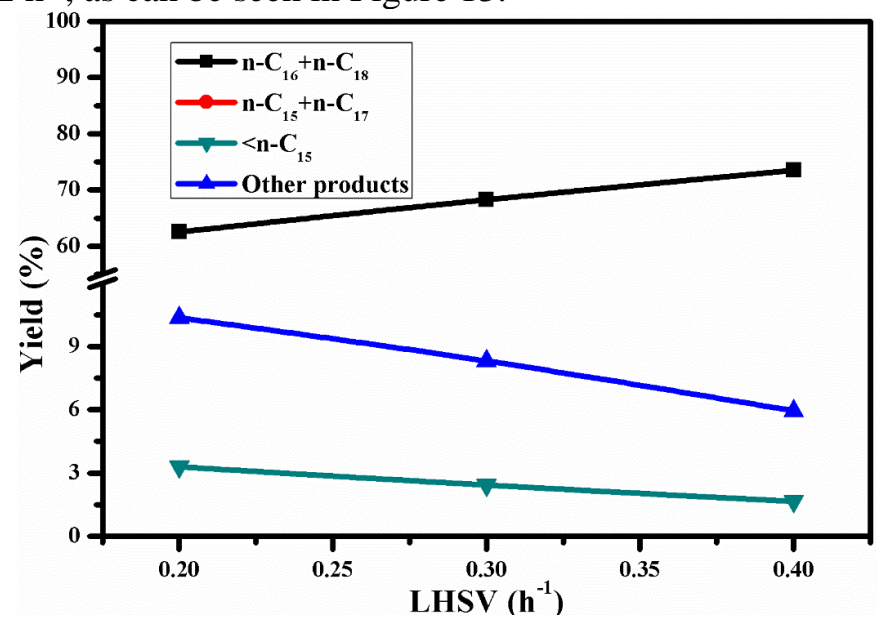

Fig. 12. The influence of the LHSV on the yield in reaction products at $340^{\circ} \mathrm{C}$ and 70 bar

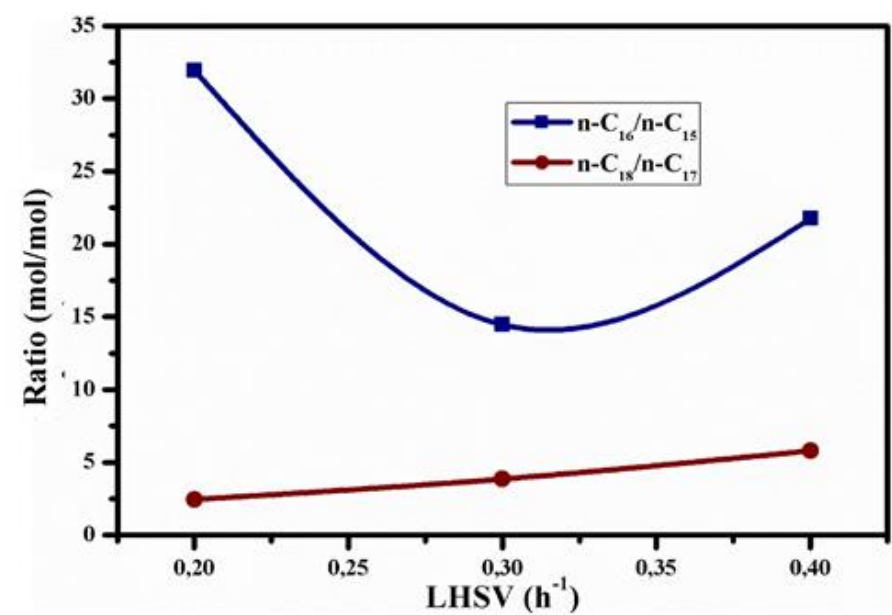

Fig. 13. The influence of LHSV on the molar ratios $\mathrm{nC}_{18} / \mathrm{nC}_{17}$ şi $\mathrm{nC}_{16} / \mathrm{nC}_{15}$ at $340^{\circ} \mathrm{C}$ and 70 bar 


\section{Conclusions}

The catalyst contains predominantly weak acidic centers and the mesopore size distribution of the catalyst is between 2 and $11 \mathrm{~nm}$ with a average pore diameter of $4.314 \mathrm{~nm}$.

Hydroconversion of the residual fraction of fatty acids from sunflower oil, was carried out on a continuous reactor, with a fixed catalyst layer.

The reaction products where mainly linear hydrocarbons C15, C16, C17 and C18 and shorter chain hydrocarbons $<\mathrm{C} 15$ and no oxygenated products, alkene or iso-alkane were identified.

The conversion of the residual fraction of fatty acids from sunflower had high values in the field of temperature variation, pressure and liquid hourly space velocity studied.

At the values of the operating parameters studied, the yield in hydrocarbons obtained by decarboxylation / decarbonylation and by hydrocraking are lower than the yield in hydrocarbons obtained by hydrodeoxygenation.

The yield in hydrocarbons formed by decarboxylation / decarbonylation, decreases with increasing temperature, while the yield in hydrocracking products increases with temperature.

\section{References}

1. MA, F., HANNA, M.A., Bioresource Technology, 1999, 70(1), p. 1-15.

2. CRISTEA, S., BOLOCAN, I., BOMBOS, D., BOMBOS, M., JUGANARU, T., Hydrogenation of Triglycerides over Ni-Mo Catalyst, Rev.Chim.

(Bucharest), 66, no. 3, 2015, p. 404-407.

3. CRISTEA, S., BOLOCAN, I., BOMBOS, D., BOMBOS, M., VASILIEVICI, G., JUGANARU, T., CHIVU, R., PANAITESCU, C., Hydrogenolisis of Sunflower Oil over Co-Mo Catalyst, Rev.Chim. (Bucharest), 66, no. 8, 2015, p.1177-1180.

4. BOMBOS, M., CRISTEA, S., OPRESCU, E.-E, BOMBOS, D., VASILIEVICI, G., BOLOCAN, I., Hydroconversion of triglycerides from sunflower oil on Ru / $\gamma$ - alumina catalysts, Rev.Chim. (Bucharest), 66, no. 11, 2015, , p. 1810-1813.

5. VELEA,. S., BOMBOS, M., VASILIEVICI, G., DOUKEH, R., BOMBOS, D., Component for Gasoline by Hydroconversion of Furfural Derivates in Presence of Methanol, Rev.Chim. (Bucharest), 68 , no. 7, 2017, p.1512-1517.

6. BOMBOŞ, D., VELEA, S., BOMBOŞ, M., VASILIEVICI, G., OPRESCU, E.E., Ecological Component for Motor Fuels Based on Furfural Derivates Rev.Chim. (Bucharest), 67, no.4, 2016, p.745-750

7. BOMBOŞ, D., VELEA, S., BOMBOŞ,M., VASILIEVICI, G.,ROSCA, P., Hydroconversion of Furfural Derivates on Ni-Co-Mo Catalysts Rev.Chim. (Bucharest), 67, no. 10, 2016, p.2034-2038

8. ZHAROVA, P.A., CHISTYAKOV, A.V., SHAPOVALOV, S.S., PASYNSKII, A.A., TSODIKOV, M.V., Original Pt-Sn/Al2O3 catalyst for selective hydrodeoxygenation of vegetable oils. Energy, 2019, 172, p. 18-25.

9. DOUKEH, R., TRIFOI, A., BOMBOȘ, M., BANU, I., PASARE, M., BOLOCAN, I., Hydrodesulphurization of thiophene over Co, Mo and CoMo/ $\square-\mathrm{Al} 2 \mathrm{O} 3$ Catalysts, Rev.Chim. (Bucharest), 69, no. 2, 2018, p 396-399.

10.DOUKEH, R., BOMBOȘ, M., TRIFOI, A., PASARE, M., BANU, I., BOLOCAN, I., Dimethyldisulphide hydrodesulphurization on NiCoMo/Al2O3 catalyst, Rev.Chim. (Bucharest), 68, no. 7, 2017, p. 1496-1500.

11. DOUKEH, R., BOMBOȘ, M., POPOVICI, D., PASARE, M., BOLOCAN, I.,Effect of Support on the Performance of CoMoRe Catalyst in Thiophene and Benzothiophene Hydrodesulfurization, Rev.Chim. (Bucharest), 70, no. 1, 2019, p. 27-32.

12. DOUKEH, R., BOMBOȘ, M., MOLDOVAN, M., BOLOCAN, I., Hydrodesulphurization of thiophenes over CoMoRe/ ZSM5- $\gamma$-Al2O3 Catalyst, Rev.Chim. (Bucharest), 69, no. 6, 2018, p. 1386-1390.

13. SANTILLAN-JIMENEZ, E., CROCKER, M., Catalytic deoxygenation of fatty acids and their derivatives to hydrocarbon fuels via decarboxylation/decarbonylation. Journal of Chemical Technology \& Biotechnology, 2012. 87(8), p. 1041-1050.

14. CHU, P. L., VANDERGHEM, C., MACLEAN, H. L., SAVILLE, B. A., Process modeling of hydrodeoxygenation to produce renewable jet fuel and other hydrocarbon fuels, Fuel, 2017, 196, p. 298-305.

15. GOSSELINK, R.W., HOLLAK, S.A., CHANG S.W., van HAVEREN, J., de JONG, K.P., BITTER, J.H., van ES, D.S., Reaction Pathways for the Deoxygenation of Vegetable Oils and Related Model Compound, ChemSusChem, 2013. 6(9), p. 1576-1594.

16. HERMIDA, L., ABDULLAH,A.Z., MOHAMED,A.R., Deoxygenation of fatty acid to produce diesel-like hydrocarbons: A review of process conditions, reaction kinetics and mechanism, Renewable and Sustainable Energy Reviews, 2015,42, p. 1223-1233.

17. LUP, A. N. K., ABNISA, F., WAN DAUD, M. A., AROUA, M. K., A review on reaction mechanisms of metal-catalyzed deoxygenation process in bio-oil model compounds, Applied Catalysis A: General, 2017, 541, p. 87-106.

18. SNARE, M., KUBICKOVA, I., MAKI-ARVELA, P., CHICHOVA, D., ERANEN, K., MURZIN, D.Y., Catalytic deoxygenation of unsaturated renewable feedstocks for production of diesel fuel hydrocarbons. Fuel, 2008, 87(6), p. 933-945.

19. STEPACHEVA, A. A., SAPUNOV, V. N., SUlMAN, E. M., NIKOSHVILI, L. Z., SULMAN, M. G., SIDOROV, A. I., DEMIDENKO, G. N., MATVEEVA, V. G., Catalytic Hydrodeoxygenation of Fatty Acids for Biodiesel Production. Bulletin of Chemical Reaction Engineering \& Catalysis, 2016, 11(2), p. 125-132.

20. ARORA, P., GRENNFELT, E. L., OLSSON, L., D. CREASER, Kinetic study of hydrodeoxygenation of stearic acid as model compound for renewable oils, Chemical Engineering Journal, 2019. 364, p. 376-389.

21. HORACEK, J., TISLER, Z., RUBAS, V., KUBICKA, D., HDO catalysts for triglycerides conversion into pyrolysis and isomerization feedstock, Fuel, 2014, 121, p. 57-64.

22. POPESCU (STANICA), A. I., BOMBOȘ, M., DOUKEH, R., BOMBOȘ, D., BOLOCAN, I., Acidity Influence of Ru Catalysts on the Hydrogenation of Naphtalene Rev.Chim. (Bucharest), 67, no.3, 2016, p 570-574.

23. DOUKEH, R., BOMBOȘ, M., TRIFOI, A., MIHAI, O., POPOVICI, D., BOLOCAN, I., BOMBOȘ, D., Kinetics of thiophene hydrodesulphurization over supported Mo-Co-Ni catalyst, Comptes Rendus Chimie, 2018,21(3), p. 277-287.

Manuscript received: 2.08 .2019 